\title{
Balancing of assembly operations and detailed design of workplace in software environment
}

\author{
Radovan Svitek ${ }^{1}$, Martin Krajčovič ${ }^{1}$, Milan Martinkovič ${ }^{1}$ \\ ${ }_{1}$ University of Žilina, Faculty of Mechanical Engineering, Department of Industrial \\ Engineering \\ Univerzitná 1, 01026 Žilina, Slovakia \\ radovan.svitek@fstroj.uniza.sk \\ martin.krajcovic@fstroj.uniza.sk \\ milan.martinkovic@fstroj.uniza.sk
}

\begin{abstract}
Factories emphasize increasing the efficiency of internal processes. Production plants therefore need a true picture of their current situation, risks and opportunities so that their presence on the market is not jeopardized and their processes effectively managed. All of this will only be possible through the implementation of new technologies and the transformation of existing factories through digitization. This combination must be based on the scheduling currently provided by interactive software scheduling systems. The article deals with the use of software solution for balancing assembly operations and detailed design of the workplace.
\end{abstract}

\section{Introduction}

Modern industrial practice can propose innovative solutions at the level of production and installation or whole production or logistics systems [1]. In order to implement new technologies, be possible combined measures of persistent and available technologies. By identifying them, it is possible for businesses to identify potential trends and add a number of innovative new challenges.

\section{Defining current design problems}

Ensuring continuity and quality of production leads some organizations to think about the current state of logistics, production and assembly systems. Management lacks data, information, methods and tools for clear decision making. The problem is that planning - managing production, logistics and other departments is based on principles that have been in use for over a hundred years.

Over the last twenty years, Lean Management and Six Sigma have been successfully applied - the factories have really advanced. But today it is not enough. The combination of these principles with digitization brings a whole new quality of data needed for decision making [2]. 
This combination must be based on the scheduling currently provided by interactive software scheduling systems. The article deals with own research in the field of using software solution for balancing assembly operations and detailed design of assembly workplace.

The research is carried out in a manufacturing company in the heavy machinery sector. The current problems related to the design of assembly workplaces after analyzing the current situation in the company include:

- Inaccurate planning due to inaccurate or incomplete data.

- Missing or inefficient software, shortcomings in information flow.

- Human errors resulting from inadequate work, lack of rules, motivation.

- Oversized or undersized capacities - people, transport equipment, areas, warehouses.

- Inappropriate logistics strategy - fixed warehouses, chaotic storage, outsourcing, insourcing.

- Problematic data acquisition, insufficient data validity and outdated.

- Insufficient overview of material flow, work activities.

\section{How to solve the problem}

Good practice, which has been of a high standard, is now complemented by new technologies. Designing, in fact, consists of collecting information, processing it, making analyzes, finding the best design and verifying it. It is an old, well-known methodological procedure, but new technological possibilities give it a completely different dimension and added value [3].

A digital copy of a real system is much easier to analyze using a software tool than would have been done in the past.

The solution was used Ceit Table software, which was the subject of research in previous activities. The design of logistics systems in software is based on the very beginning of the processing of input data. The basic input data necessary for the analysis of the logistics system can be divided into the following categories:

- Part data: part number and name, part weight, type of package, number of pieces in package, length, width, package height, net package weight and stackability.

- Manufacturing process data: manufacturing process with basic information (operation number, operation name, unit production time, workplace / machine at which the operation will be performed).

- Available time data for each category of production resources (machine, workplace, worker): number of hours to be changed, number of usable days per year. 
- Data on current logistics supply plans, stops, number of staff and number of handling equipment

The classic design of production and logistics systems can be utilized by modern digital systems and confirm flexibility and efficiency. Making a digital copy of a real production and logistics system, depending on what is possible in the import of the current drawing of the production facility to store additional deposits of 3D objects [4].

The modeling of the production system therefore takes place on the current state. After parameterization and hierarchical assignment (Figure 1), the individual objects are modeled, and the spatial disposition is modeled using an embedded production disposition drawing.

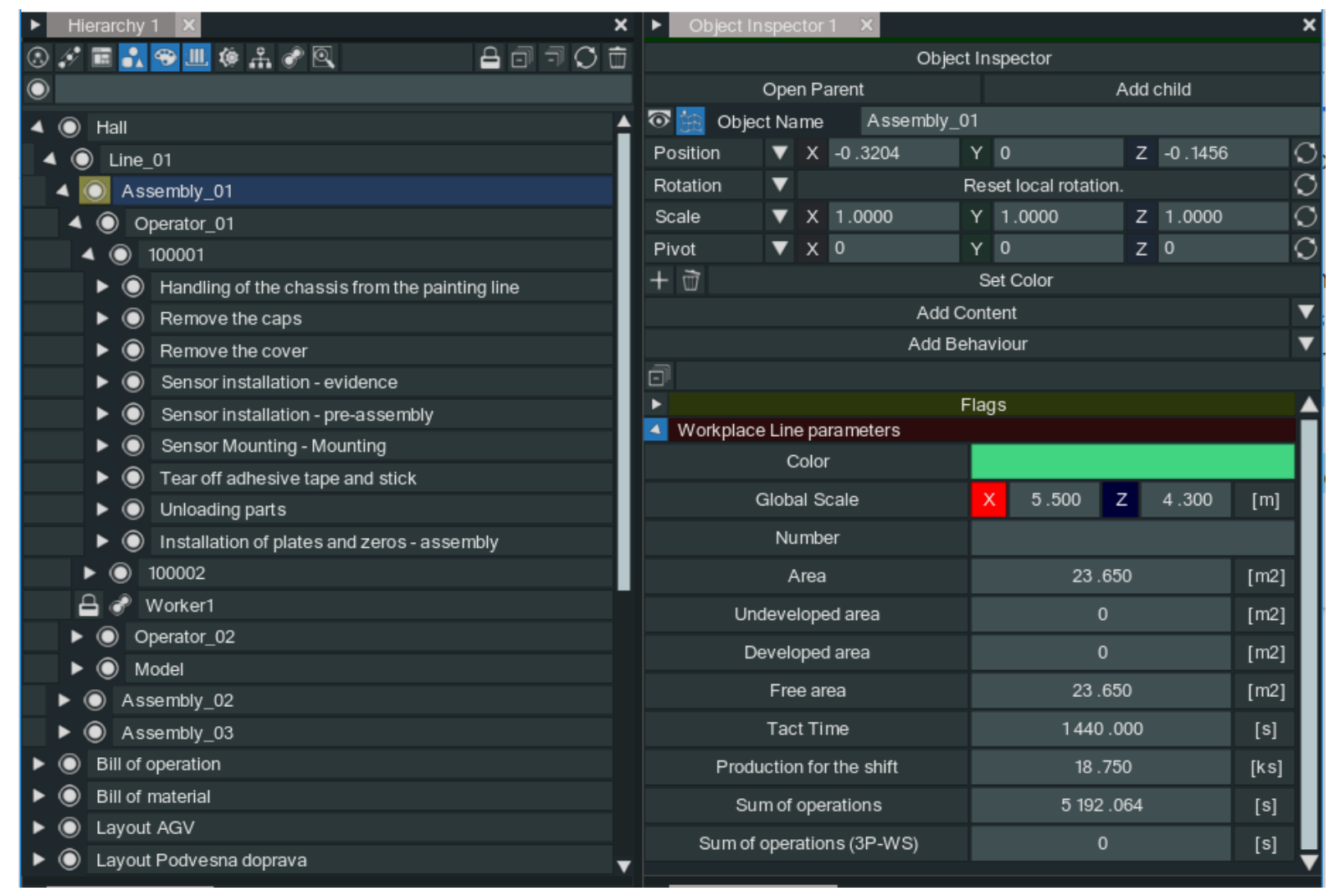

Figure 1 - Hierarchy of assembled digital production disposition model

An external file called BOO (Bill of Operations) is created from production process data (technological processes). Assembly operations are allocated according to the workflow to individual workplaces / workers (Figure 2). An external dataset was compiled for two production representatives 100 001; 100002. 


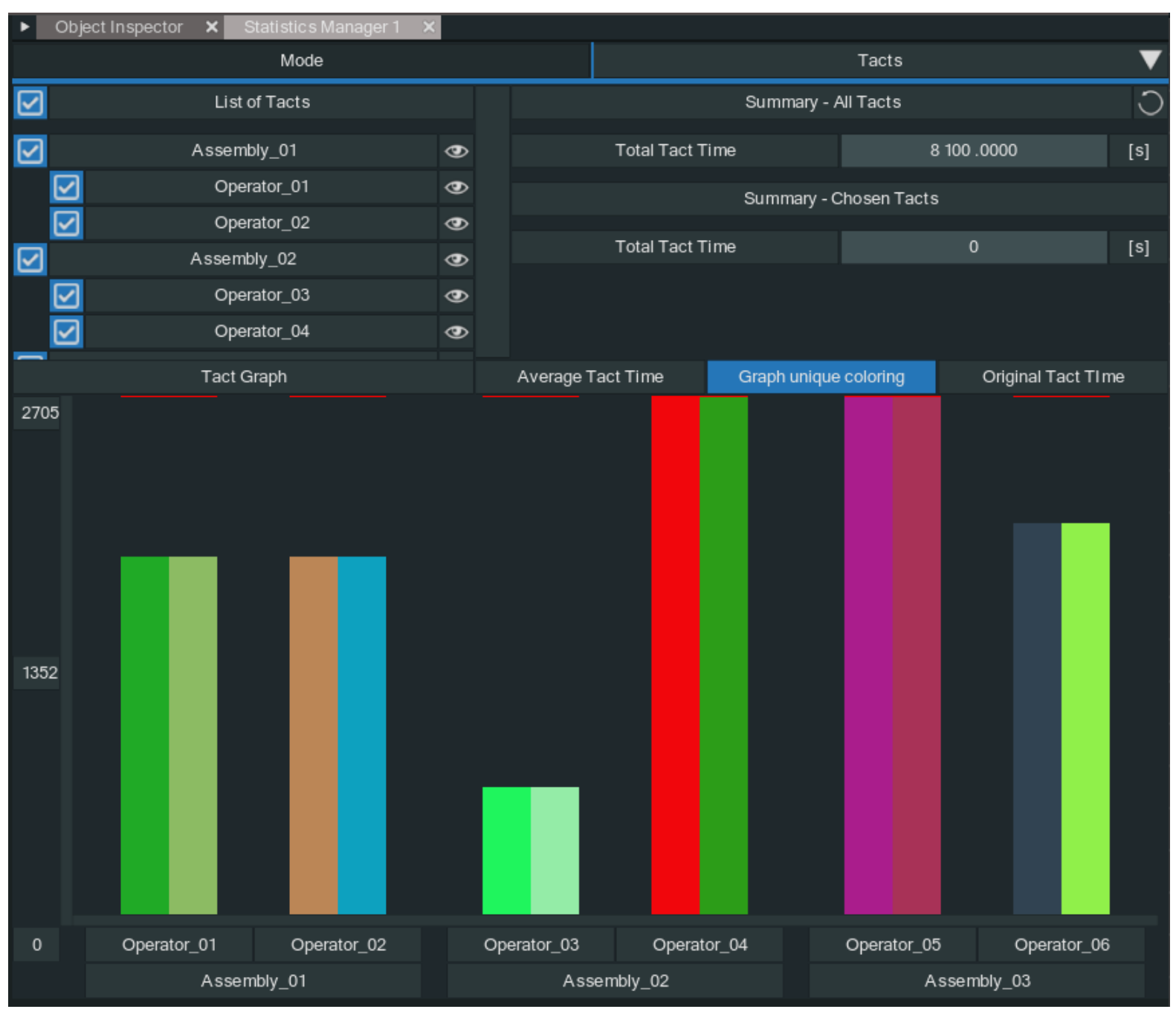

Figure 2 - Capacity utilization of individual assembly workers

The results of the analysis confirmed the above-mentioned problems in designing production and assembly systems in the company.

The software solution CEIT Table is an interactive tool for efficient team planning of production and logistics systems. It makes it easy to design a logistics or production concept using 3D models and select the best options through analyzes.

The tool includes functions and work modules that make it easier to work and make decisions when designing a new manufacturing system. After entering the input parameters, we evaluated them interactively through the tool with respect to the state and nature of the production disposition [5].

Using the MTM UAS module (Figure 3), we created by direct observation of the filmed video sequences the duration (time consumption) of the individual assembly operations. 


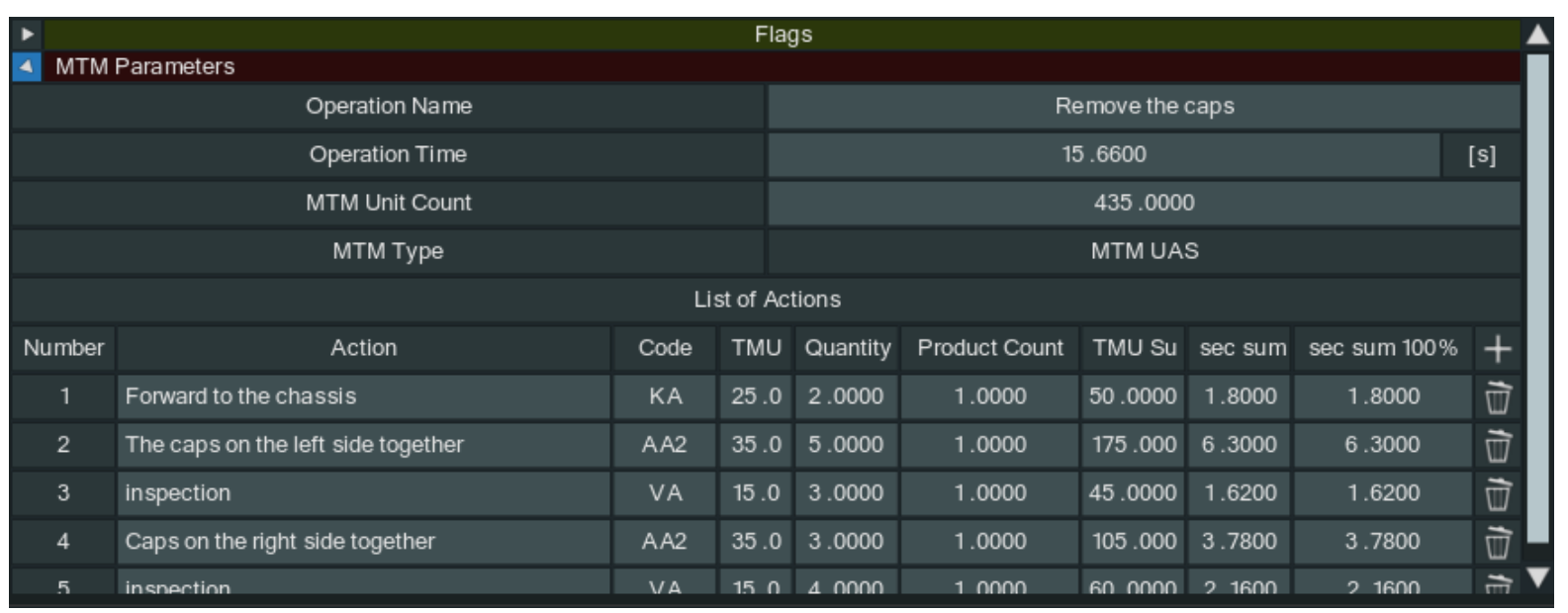

Figure 3 - Determination of activity time by direct observation of MTM UAS methodologists

Assembly workplaces in the company have the task of assembling the supporting part of the construction of high tonnage vehicle. The parts that enter the assembly process are from sources of own production and purchased items. Assembly operations are divided into three sections, assembly_01-03. The first section is designed to prepare parts of their own production after their surface treatment (painting) for assembly operations of the second section. Subsequently, the next section mounts the preassembled parts assemblies to the assembly unit, and the third section completes the wiring of the sensors, performs a visual inspection, and sends the assembly unit for a stress test.

With the help of the tool we created several variants of the layout of assembly operations for individual workplaces / workers. After making any changes, the system interactively evaluated its impact and recalculated the parameters of the proposed production system. The production system has changed:

- Distribution of operations equally to individual employees according to analyzed time consumption of given operations by MTM UAS methodology.

- Number of individual workers at each assembly site. Installation of assembly workplaces (figure 4), location of the material entering the assembly in reach zones up to 3 [m] (avoiding walking losses).

- Method of picking individual consumed parts in assembly, material kitting on demand (product - assembly).

- Interoperative handling at individual workplaces, use of overhead cranes, column manipulators for heavy parts. 


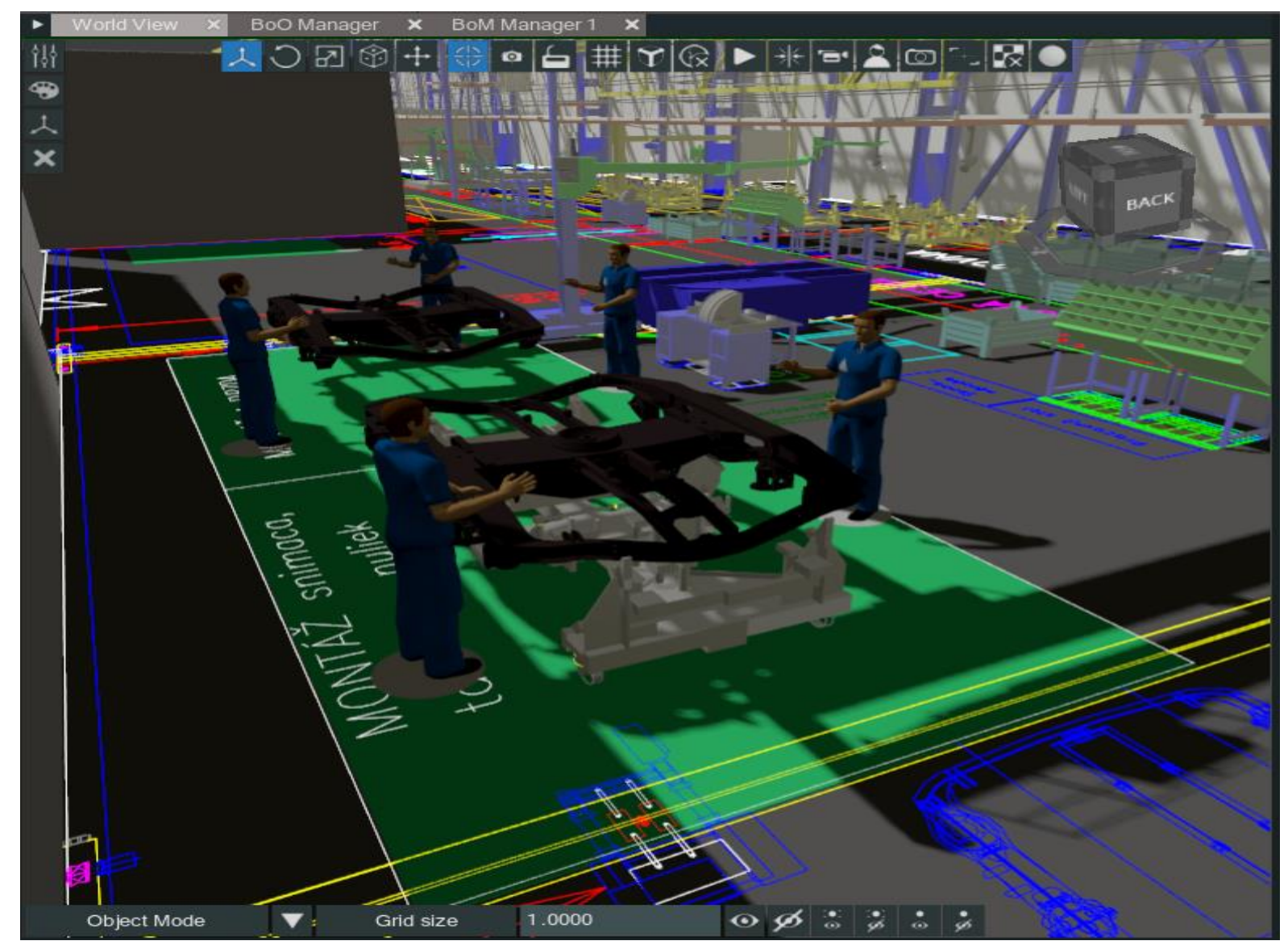

Figure 4 - Production disposition after implementation of changes in the software

Table 1 shows the parameters of the production system before and after the implementation of the defined changes. The distribution of the individual assembly operations based on the analysis of their time consumption allowed us to more optimally distribute the tasks of the assembly workplaces and thus more evenly utilize the individual workers

Together with the elimination of wastage in the form of walking or searching for material in the workplace in packaging units (material kits, material in one place) we were able to shorten the cycle of individual assembly workplaces and also the total running time of production. The permeability of assembly workplaces will be increased by 8 products per change, which represents a significant increase over the current situation.

Table 1 - Basic parameters of the production system before and after changes

\begin{tabular}{|c|c|c|c|}
\hline $\begin{array}{c}\text { Number of } \\
\text { employees: }\end{array}$ & Tact: & $\begin{array}{c}\text { Continuous } \\
\text { production time: }\end{array}$ & Throughput: \\
\hline 5 workers & $2700[\mathrm{sec}]$ & $8100[\mathrm{sec}]$ & 10 products/ change \\
\hline 6 workers & $1440[\mathrm{sec}]$ & $4320[\mathrm{sec}]$ & 18 products/ change \\
\hline
\end{tabular}


For the purposes of these changes, it was possible to optimally design assembly workstations for a particular production system. In Figure 5 it is possible to request their capacity utilization after realized cases.

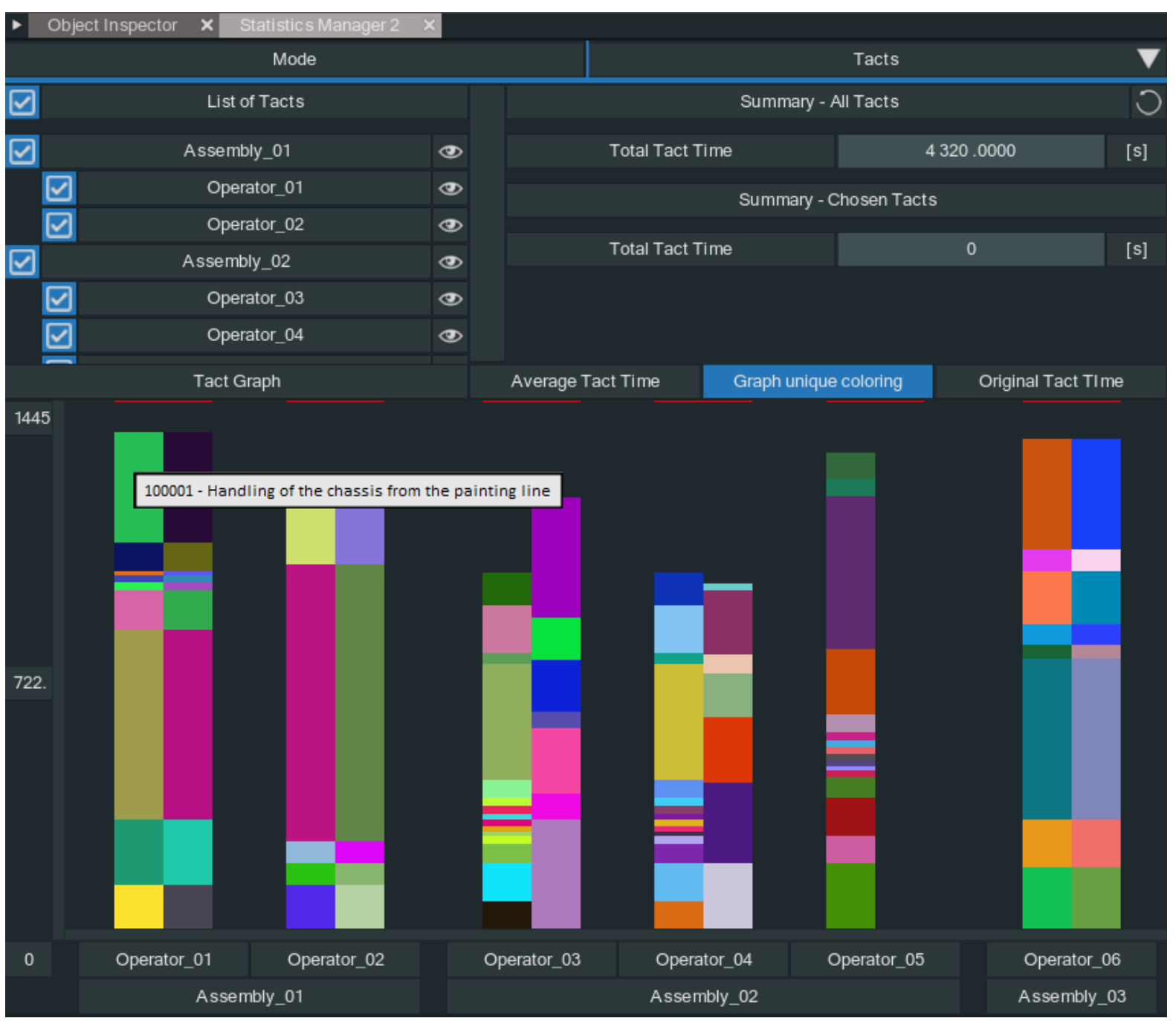

Figure 5 - Capacity design of individual assembly workers

The production layout of the new hall is not a problem to create today but debugging processes in real operation is not only laborious, but especially very expensive. In addition, some collisions could remain undetected, which would cause problems later. Using a parametric planning system, however, it is possible to identify and remedy shortcomings in planning. Subsequent visualization then allows the final check. Many factories do not realize the fact that modern technologies and advanced approaches give us the possibility of a huge lead.

CEIT Table software solution is a tool for designing production and assembly system in 3D environment. The system includes functions and work modules that make it easier to work and make decisions when designing production layouts and assembly systems. The design of production and logistics 
systems is realized by means of $2 \mathrm{D} / 3 \mathrm{D}$ models. After making any change, the system interactively evaluates the change and recalculates the parameters of the proposed production system.

Based on the results mentioned in this article, the team concludes that we can use the software solution resulting from the previous research to solve complex problems that arise in the detailed design of the assembly workplace.

\section{Conclusion}

New functionalities of software solutions are now indispensable in creating and evaluating the design of complex manufacturing and logistics structures. Software solutions that stimulate the communication and interaction of individual system objects offer an efficient design tool that can be changed without the need to change each element of the system. This means that changing a system element recalculates individual parameters and relationships between other system objects. The system reacts flexibly to changes and with its help it is possible to determine how the entered changes will affect the system in a broader understanding. Thus, a supporting design tool with interconnected and communicating elements can convey information and feedback in the process of making changes for further decision making of industrial organizations.

\section{Acknowledgement}

This work was supported by the Slovak Research and Development Agency under the contract no. APVV-16-0488.

\section{References}

[1] Gregor, M., Hodoň, R., Biňasová, V., Dulina, L., Gašo, M. Design of simulation-emulation logistics system. In: MM Science Journal, 2018, no. 3, s. 2498-2502. ISSN 1803-1269.

[2] Miebach, J., Müller, P. Intralogistik - Potentiale, Perspektiven, Prognosen. Springer, Berlin, Germany, 2006. ISBN 978-3-540-29657-7.

[3] Mičieta, B., Gašo, M., Krajčovič, M. Innovation performance of organization. In: Communications - Scientific letters of the University of Žilina, 2014, vol. 16, no. 3A, s. 112-118, ISSN 1335-4205.

[4] Furmann, R., Furmannová, B. Logistics and Digital Twin. In: InvEnt: Industrial Engineering - Invention for Enterprise, 2017, p. 40-44. ISBN 97883-947909-0-5.

[5] Ceit Table, 2019. Ceit Table ver. 3.2.1. - technická dokumentácia (Užívatel'ský manuál). Spoločnost' Ceit a.s., 2019, p. 129. 